\title{
Experience of danaparoid to treat vaccine- induced immune thrombocytopenia and thrombosis, VITT
}

\author{
Lasse Myllylahti ${ }^{1}$, Hanna Pitkänen ${ }^{2,3}$, Harry Magnani $^{4}$ and Riitta Lassila ${ }^{5,6^{*}}$
}

\begin{abstract}
Background: Vaccine-induced immune thrombocytopenia and thrombosis (VITT) is triggered by nCOV-19 adenovirus-vectored vaccines against SARS-CoV2. Pathogenesis has been mainly related to platelet activation via PF4-reactive antibodies that activate platelets and may cross-react with heparin. Data concerning optimal anticoagulation are anecdotal, and so far, there are scattered reports of danaparoid use in VITT management. Danaparoid has good efficacy and safety in treatment of heparin-induced thrombocytopenia. We report here our experience of the administration and monitoring danaparoid in VITT.
\end{abstract}

Methods: We diagnosed a series of six hospitalized cases of VITT, based on the international diagnostic guidance. All VITT-related data were from the local electronic medical and laboratory record system and were analyzed with IBM SPSS Statistics.

Results: Predominately women in their late 40's developed VITT on average 24 days (range 9-59) after the first ChAdOx1 dose. Clinical presentation included single or multiple venous and/or arterial thrombosis, moderate thrombocytopenia and high D-dimer levels. After detecting PF4 antibodies subcutaneous danaparoid was our firstline antithrombotic treatment with an average duration of three weeks. The median plasma anti-FXa activity was in the lower part of the therapeutic range and during the first week of danaparoid administration clinical symptoms, platelet counts, and fibrin turnover resolved or significantly improved. The average duration of hospital admission was 10 days [2-18]. One patient died but the other five patients recovered completely.

Conclusions: The clinical outcomes of our small cohort align with the earlier published reports, and support danaparoid as a rational option for the initial anticoagulation of VITT patients.

Keywords: COVID19, Vaccination, PF4 antibody, VITT, Autoimmune HIT, Danaparoid sodium, Clinical case series

\footnotetext{
* Correspondence: riitta.lassila@hus.fi

${ }^{5}$ Unit of Coagulation Disorders, Department of Hematology, Comprehensive

Cancer Center, Helsinki University Hospital, and Research Program Unit in

Systems Oncology, University of Helsinki, Haartmaninkatu 8, 00290 Helsinki,

Finland

${ }^{6}$ Finnish Institute of Health and Welfare, Helsinki, Finland

Full list of author information is available at the end of the article
}

(c) The Author(s). 2022 Open Access This article is licensed under a Creative Commons Attribution 4.0 International License, which permits use, sharing, adaptation, distribution and reproduction in any medium or format, as long as you give appropriate credit to the original author(s) and the source, provide a link to the Creative Commons licence, and indicate if changes were made. The images or other third party material in this article are included in the article's Creative Commons licence, unless indicated otherwise in a credit line to the material. If material is not included in the article's Creative Commons licence and your intended use is not permitted by statutory regulation or exceeds the permitted use, you will need to obtain permission directly from the copyright holder. To view a copy of this licence, visit http://creativecommons.org/licenses/by/4.0/ The Creative Commons Public Domain Dedication waiver (http://creativecommons.org/publicdomain/zero/1.0/) applies to the data made available in this article, unless otherwise stated in a credit line to the data. 


\section{Introduction}

Global outbreak of severe acute respiratory syndrome coronavirus 2 (SARS-CoV-2) infections emerged early in 2020. The vaccination program has been critical in control of the pandemic due to its robust efficacy and safety [1-4]. However, in March 2021, concerns arose over emerging reports of immune thrombotic syndromes after nCOV19 adenoviral vector vaccination $[5,6]$. Some patients suffered combined thrombocytopenia and a clinical course of multiple and/or unusually sited thrombosis, including cerebral venous sinus (CVST) and splanchnic vein thrombosis, as well as arterial events [5-7]. Most typical biomarkers included low platelet and high fibrin D-dimer levels and plateletactivating anti-PF4 antibodies (by ELISA method, rapid immunoassays are usually negative) without previous heparin exposure $[7,8]$. Before the pandemic, anti-PF4 antibodies and thrombocytopenia were rare amongst patients suffering from CVST [9]. Clinical presentation mimicked the condition previously reported as autoimmune or spontaneous heparin-induced thrombocytopenia (aHIT) [10]. The condition is now known as vaccine induced immune thrombocytopenia and thrombosis (VITT) [ 8] or thrombosis with thrombocytopenia syndrome (TTS) by WHO [11].

Treatment options of VITT are based on the experience from other anti-heparin/PF4 antibody - related disorders of HIT and aHIT. Anticoagulation with preferably a non-heparin agent and administration of intravenous immune globulin (IVIG) are recommended to restrain the pathological platelet activation $[8,10]$. The optimal anticoagulant for the initial administration is unclear, direct parenteral thrombin inhibitors, argatroban and bivalirudin, as well as danaparoid and fondaparinux are options, and the direct oral anticoagulants (DOACs) appear to be suitable, at least in the later course of the disease $[8,10,11]$.

Danaparoid sodium is a non-heparin glycosaminoglycan antithrombotic that inhibits thrombin generation. It has been successfully used for HIT and its alternative administration routes (intravenous and subcutaneous) provide practical options for both inpatient and outpatient administration [12]. Unlike other agents, danaparoid is capable to detach PF4 from the platelet surface and disrupt PF4 containing immune complexes [10]. Hence theoretically, danaparoid should have a direct influence on VITT pathogenesis beyond its anticoagulant action $[10,13]$. Our local guidance for initial anticoagulation during the acute treatment of HIT includes danaparoid, administered either intravenously (loading bolus 1250-3750 U with subsequent tapered infusion till 150$200 \mathrm{U} / \mathrm{h}$ ) or subcutaneously at doses of 750-1500 U, 23 times a day with targeted anti-FXa activity of $0.3-0.5$ $\mathrm{U} / \mathrm{mL}$ [14]. There are a few reports of danaparoid use for treatment of HIT during COVID-19 [15, 16] or thrombosis post vaccination [17-20]. In this study, we want to share our experience of its use to treat VITT.

\section{Patients and methods}

Our adapted diagnostic guidance requires previous nCOV19 adenovirus-vectored vaccination (usually 4-30 days before presentation), evidence of new thrombosis and thrombocytopenia and a positive anti-heparin/PF4 antibody ELISA test to confirm a diagnosis of VITT $[8,21]$.

Our study was accepted by the Helsinki University Ethical Committee (HUS/1238/2020). Written informed consents were received from patients 2 to 6 and from a close relative of patient 1 . We collected all available VITT episode -related clinical and laboratory data from local electronic medical and laboratory record systems (EPIC Apotti, Weblab Clinical). IBM SPSS Statistics 25 was used to describe and analyze the collected data (Descriptive Statistics package) and Prism version 9 to visualize the data.

Our main focus was to evaluate all patients' medical history, date of vaccination, prior heparin exposure $(<$ 6 months before current presentation), initial clinical presentation with laboratory and coagulation biomarker statuses, initial antithrombotic medication and detection of anti-heparin/PF4 antibodies (ELISA, Asserachrom HPIA, Diagnostica Stago, France). In addition, administration of intravenous immune globulin (IVIG), clinical course during hospital admission, administration of danaparoid and its anti-FXa -activity $(\mathrm{U} / \mathrm{mL}$, HemosIL Liquis Anti-Xa, Mediq Suomi Oy), and final clinical outcome were recorded when examining the raw health information data. The aim of the anti-FXa activity levels during subcutaneous danaparoid administration was $0.3-0.5 \mathrm{U} / \mathrm{mL}$.

With respect to the systematic coagulation analysis, we screened coagulation times including prothrombin time (Medirox Owren's PT (\%) Medirox, Nyköping, Sweden), activated partial thromboplastin time (APTT (seconds, reference range 28-37 s) Actin $\mathrm{FSL}^{\circ}$, Siemens) and thrombin time (seconds, reference range 17-24s BC Thrombin reagent, Siemens). Antithrombin activity (AT, (\%) reference range 85-125\%) was captured with a chromogenic assay (Berichrom Antithrombin III). We also analyzed fibrinogen level (g/L, reference range 2.0$4.0 \mathrm{~g} / \mathrm{L}$, Clauss method, HemosIL Q.F.A. Thrombin, Werfen, Barcelona, Spain), fibrin D-dimer level (mg/L, reference range $<0.5 \mathrm{mg} / \mathrm{L}$, HemosIL D-Dimer HS 500, ILS Laboratories), coagulation factor VIII activity (FVIII: C, IU/dL, one-stage clotting assay, Pathromtin SL and FVIII Deficient Plasma)). Furthermore, D-dimer to fibrinogen ratio was calculated.

We collected available data at following 5 time points: the admission day (time point 1) and dynamically from days 1-3 from admission (time point 2), days 4-7 (time 
point 3), days 8-14 (time point 4) and days 15-30 (time point 5). These time points were matched with the dynamics of platelet count and an acute phase reactant $\mathrm{C}$ reactive protein $(\mathrm{CRP})$.

\section{Patient 1}

A 40-year-old man with history of hypertension, obesity (145 $\mathrm{Kg}$ and BMI $40 \mathrm{Kg} / \mathrm{m}$ ), type 2 diabetes, achalasia, and sleep apnea, was admitted to hospital 9 days after his first dose of ChAdOx1 with complaints of fever, arthralgia and chest pain. Thrombocytopenia $\left(40 \times 10^{9}\right.$ / $\mathrm{L}$ ), extreme fibrin turnover (D-dimer $>128 \mathrm{mg} / \mathrm{L}$ ) and acute myocardial infarction (AMI) were identified. Contrast head computer tomography (CT) scan was diagnostic for CVST with extensive clot burden and secondary intracranial hemorrhage ( $\mathrm{ICH})$ due to increased venous pressure. After detection of anti-PF4 antibodies by ELISA, intravenous danaparoid (loading bolus of $1500 \mathrm{U}$ with subsequent infusion of 250 to $330 \mathrm{U} / \mathrm{h}$ ) was initiated and platelets, fresh frozen plasma and fibrinogen were supplemented because of continued bleeding. IVIG was administered and decompressive hemicraniectomy was performed. However, clinical course deteriorated, and the patient died two days after the admission.

\section{Patient 2}

A 21-year-old woman with BMI of $30.3 \mathrm{Kg} / \mathrm{m}^{2}(94.5 \mathrm{Kg})$ was in remission from acute lymphoblastic leukemia (ALL) after allogenic stem cell transplantation. Beyond that, she had type 1 diabetes and chronic pain issues. She was admitted to hospital 12 days after her first ChAdOx1 dose with recurrent headache, elevated D-dimer $(12 \mathrm{mg} / \mathrm{L})$ and new thrombocytopenia $\left(54 \times 10^{9} / \mathrm{L}\right)$. Head MRI scan revealed extensive CVST. On day 5 after admission anti-PF4 antibodies were positive by ELISA with previous negative rapid test. Anticoagulation was switched from tinzaparin to subcutaneous danaparoid $(1250 \mathrm{U} \times 2$, later $1250 \mathrm{U}+750 \mathrm{U})$ and IVIG $0.4 \mathrm{~g} / \mathrm{Kg} /$ day for five consecutive days was administered. This cotreatment led to recovery and the patient could be discharged after 15 days of admission with self-injections of danaparoid. Two months later anticoagulation was switched to fondaparinux for another month by which time the patient had fully recovered and a control head MRI scan was negative for residual CVST.

\section{Patient 3}

A 52-year-old man with BMI of $24 \mathrm{Kg} / \mathrm{m}^{2}(77 \mathrm{Kg})$ with dyslipidemia, paroxysmal atrial fibrillation with low arrythmia burden (no prior anticoagulation) and aortic stenosis. 9 days after his first ChaAdOx1 dose he was admitted to hospital with headache and chest pain. AMI was diagnosed and percutaneous coronary intervention was performed. Thrombocytopenia $\left(55 \times 10^{9} / \mathrm{L}\right)$ and strongly elevated D-dimer (101 mg/L) were found. After detection of anti-PF4 antibodies by ELISA, IVIG $1 \mathrm{~g} / \mathrm{Kg} /$ day for two consecutive days together with subcutaneous danaparoid (initially $750 \mathrm{U} \times 2$, later $1250 \mathrm{U} \times 2$ ) were initiated. During the early phase of admission, portal vein and cephalic vein thrombosis were diagnosed. The clinical course gradually ameliorated, and the patient was discharged 18 days after admission with ambulatory self-injected danaparoid and peroral ticagrelol. Later the patient was switched to apixaban and is still taking ticagrelol. He fully recovered.

\section{Patient 4}

A 60-year-old woman had asthma and reflux esophagitis, and a history of bilateral pulmonary embolism (PE) 5 years earlier. Her BMI was $29.8 \mathrm{Kg} / \mathrm{m}^{2}$ (90 Kg). 19 days after her first ChAdOx1 dose she developed bilateral pulmonary emboli (PE) and a left tibial vein thrombosis. At this point, the platelet count was normal, and dalteparin anticoagulation was initiated. 41 days after vaccination she was re-admitted due to the onset of dizziness, headache, and nausea. CVST was excluded by contrast CT scan, but a new thrombocytopenia $\left(54 \times 10^{9} / \mathrm{L}\right)$ was detected. D-dimer was elevated $(1.1 \mathrm{mg} / \mathrm{L})$ and anti-PF4antibodies were positive in ELISA. After danaparoid $1500 \mathrm{U} \times 2 \mathrm{sc}$ was started the platelet count normalized and her clinical course improved without IVIG. The patient was discharged on day 7 after switching to oral dabigatran and indefinite anticoagulation was recommended because of the recurrent episode of PE. She fully recovered.

\section{Patient 5}

A 68-year-old woman, with no significant medical history, complained, 16 days after the first ChAdOx1 dose, of recurrent headaches. Thrombocytopenia $\left(65 \times 10^{9} / \mathrm{L}\right)$ and markedly elevated D-dimer level $(35 \mathrm{mg} / \mathrm{L})$ were found. Head MRI scan showed an extended left side CVST, and she had also a small PE with minor symptoms. Danaparoid was initiated since anti-PF4 antibodies were positive by ELISA. IVIG was administered and the clinical course, platelet count and D-dimer level responded favorably. One week after admission, she was discharged with ambulatory subcutaneous self-injected fondaparinux. She made a full recovery, and later anticoagulation was switched to oral apixaban, the duration of which is still to be evaluated.

\section{Patient 6}

A 42-year-old woman with sleep apnea and obesity (109 $\mathrm{Kg}$ with BMI $38 \mathrm{Kg} / \mathrm{m}^{2}$ ) was admitted to hospital 59 days after her first ChAdOx1 dose with recent symptoms of headache, common cold and myalgia. Initial laboratory evaluation identified thrombocytopenia $\left(73 \times 10^{9} / \mathrm{L}\right)$ 
Table 1 Baseline clinical characteristics and laboratory observations

\begin{tabular}{|c|c|c|c|c|c|c|}
\hline Patient & 1 & 2 & 3 & 4 & 5 & 6 \\
\hline Age & 40 & 21 & 52 & 60 & 68 & 42 \\
\hline Sex & M & $\mathrm{F}$ & M & $\mathrm{F}$ & $\mathrm{F}$ & $\mathrm{F}$ \\
\hline Admission - days after vaccination & 9 & 12 & 9 & 41 & 16 & 59 \\
\hline Prior exposure to a heparin & No & No & No & Yes & No & No \\
\hline Hemoglobin (M134-167, F 117-155 g/L) & 147 & 106 & 146 & 116 & N/A & N/A \\
\hline WBC Count $\left(\times 10^{9} / \mathrm{L}\right)\left(3.4-8.2 \times 10^{9} / \mathrm{L}\right)$ & 6.1 & 5.5 & 5.4 & 5 & N/A & N/A \\
\hline Neutrophilia or monocytosis & Yes & No & Yes & Yes & N/A & N/A \\
\hline $\operatorname{ALT}(\mathrm{U} / \mathrm{L})(<50 \mathrm{U} / \mathrm{L})$ & 127 & 12 & 55 & 55 & N/A & N/A \\
\hline
\end{tabular}

(reference values), N/A = not available.

Nadir since admission to a distant hospital.

and high D dimer $(20.4 \mathrm{mg} / \mathrm{L})$. Bilateral PE was diagnosed by contrast CT scan, and she was commenced on enoxaparin. The platelet count remained low, thromboinflammatory activity persisted, and her clinical course did not improve. Head MRI scan revealed a left internal jugular vein thrombosis and abdominal contrast CT scan identified extended portal vein thrombosis. Anti-PF4 antibodies were negative by rapid immunoassay but due to technical reasons initial ELISA samples were unavailable. However, clinical suspicion of probable late onset VITT was raised hence IVIG ( $1 \mathrm{~g} / \mathrm{Kg}$ for two consecutive days) together with subcutaneous danaparoid were initiated. The thrombocytopenia and thrombotic activity recovered and her clinical course gradually improved. After two weeks of danaparoid anticoagulation she was commenced on oral apixaban for 12 months, and made a full recovery.

\section{Results}

\section{Clinical data}

In Finland, the ChAdOx1 nCOV-19 (Vaxzevria ${ }^{\circ}$, Astra Zeneca) has been used for all adenoviral COVID-19 vaccinations. By the end of the May 2021, the number of first ChAdOx1 doses was 358,000 , and 55,000 people had completed their vaccination program with the two ChAdOx1 doses [22].

We diagnosed six VITT cases in Finland between midMarch and May 2021 after the first vaccination dose, and the use of this vaccine was discontinued in April 2021. According to international diagnostic criteria [8, 23], patients 1-3 and 5 were classified with definite and patients 4 and 6 with possible VITT, but we consider that all cases represent the spectrum of VITT disease. The mean age of our predominately female $(4 / 6) \mathrm{pa}$ tients was 47 years (range 21-68 years). The mean elapsed time from the first ChAdOx1 vaccination to the Emergency Department contact was 24 (range 9-59) days (Tables 1 and 2). Half of the patients had CVST (1, 2 and 3), but other sites of thrombosis were also verified (patients 1, 3, 4, 5 and 6). Arterial events were detected in two male patients, both cases being AMI; myocarditis as a differential diagnosis in patient 1 . One patient had prior exposure to a heparin with her previous therapeutic dalteparin for a PE. The mean duration of

Table 2 VITT diagnosis, location of thrombosis, antithrombotic and IVIG therapy

\begin{tabular}{|c|c|c|c|c|c|c|}
\hline Patient & 1 & 2 & 3 & 4 & 5 & 6 \\
\hline Cerebral venous sinus thrombosis & Yes & Yes & No & No & Yes & No \\
\hline Multiple thromboses & Yes & No & Yes & Yes & Yes & Yes \\
\hline Arterial thrombosis & Yes & No & Yes & No & No & No \\
\hline $\begin{array}{l}\text { Anti-PF4 Ab ELISA positivity -Days after } \\
\text { admission }\end{array}$ & 1 & 5 & 1 & 0 & 1 & N/A \\
\hline Initial (1-2 doses) antithrombotic treatment & $\begin{array}{l}\text { enoxaparin, } \\
\text { aspirin }\end{array}$ & tinzaparin & $\begin{array}{l}\text { enoxaparin, aspirin, } \\
\text { ticagrelol }\end{array}$ & danaparoid & danaparoid & enoxaparin \\
\hline IVIG & Yes & Yes & Yes & No & Yes & Yes \\
\hline Duration of hospital stay (days) & 2 & 15 & 18 & 7 & 7 & 20 \\
\hline Outcome & Fatal & Recovery & Recovery & Recovery & Recovery & Recovery \\
\hline
\end{tabular}




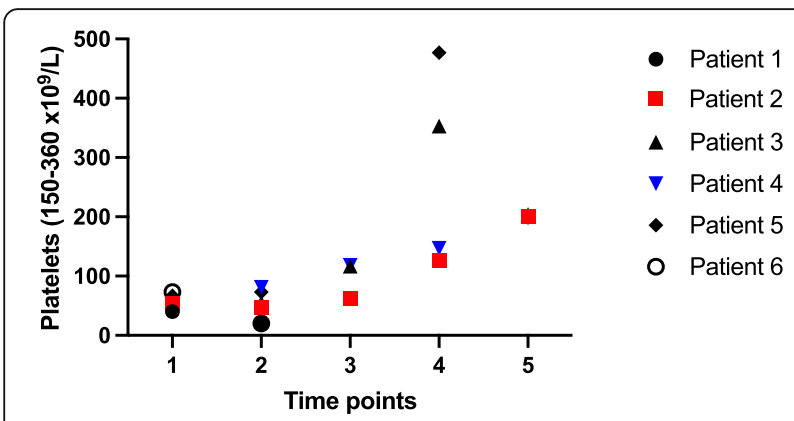

Fig. 1 Evolution of platelet counts (normal range 150-360 $\times 10^{9} / \mathrm{L}$ ) before and during danaparoid therapy. Time points: $1=$ on admission day, $2=$ at $1-3$ days, $3=4-7$ days,

$4=8-14$ days, $5=15-30$ days

hospital admission was 10 days (range $2-18$ days). Five of the six patients fully recovered but one had a fatal outcome (patient 1).

\section{Laboratory data}

The average hemoglobin level was $129 \mathrm{~g} / \mathrm{L}$ (range 106$147 \mathrm{~g} / \mathrm{L}$ ) and all patients presented with moderate thrombocytopenia (mean count $57 \times 10^{9} / \mathrm{L}$, range 40 $73 \times 10^{9} /$ L, Fig. 1) $7-14$ days after admission platelet counts had normalized to an average count of $276 \times 10^{9} /$ L (range $127-477 \times 10^{9} / \mathrm{L}$ ). Available results of general biomarkers did not identify significant liver or renal impairment. White blood cell counts were normal in all cases, but the differential analysis showed neutrophilia or monocytosis in three patients. Almost every patient presented with inflammation based on the CRP levels (mean $55 \mathrm{mg} / \mathrm{L}$; range $5-139 \mathrm{mg} / \mathrm{L}$, Fig. 2). By timepoint 4-7 days from hospitalization, inflammation already significantly attenuated (mean CRP $19 \mathrm{mg} / \mathrm{L}$; range 4-50 $\mathrm{mg} / \mathrm{L}$ ), excluding patient 6 whose diagnosis of VITT was delayed in another hospital.

We did not detect abnormalities in coagulation times of PT, APTT, thrombin time or antithrombin levels during and after the admissions. FVIII activity was elevated

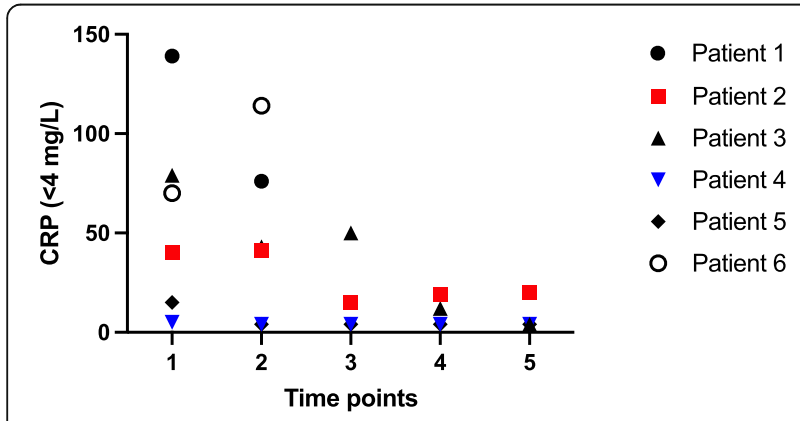

Fig. 2 Evolution of C-reactive protein (normal $<4 \mathrm{mg} / \mathrm{L}$ ) before and during danaparoid. Time points: $1=$ on admission day, 2 = at days $1-$ $3,3=$ days $4-7,4=$ days $8-14,5=$ days $15-30$

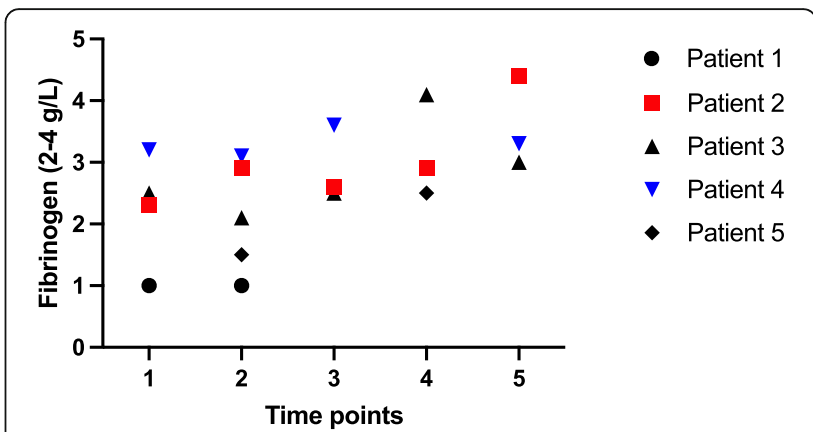

Fig. 3 Fibrinogen (normal $2-4 \mathrm{~g} / \mathrm{L}$ ) levels before and during danaparoid therapy. Time points: $1=$ on admission day, $2=$ at $1-3$ days, $3=4-7$ days, $4=8-14$ days, $5=15-30$ days

in all patients, peaking at $335 \mathrm{IU} / \mathrm{dL}$ in patient 3 at the time point 4 . Similarly, compared with other reports of VITT coagulation abnormalities [7, 8], D-dimer levels were elevated in every patient, and values exceeding 30 $\mathrm{mg} / \mathrm{l}$, in patients 1,3 and 5 , are compatible with extensive fibrin turnover ((see Fig. 4a). Furthermore, low fibrinogen levels identified in two patients (Fig. 3). D-dimer to fibrinogen ratio was extreme in patients 1 and 3, suggesting markedly enhanced fibrin degradation (Fig. 4b).

\section{Treatment data}

Five of the six patients were administered IVIG to reduce and prevent the further pathological platelet

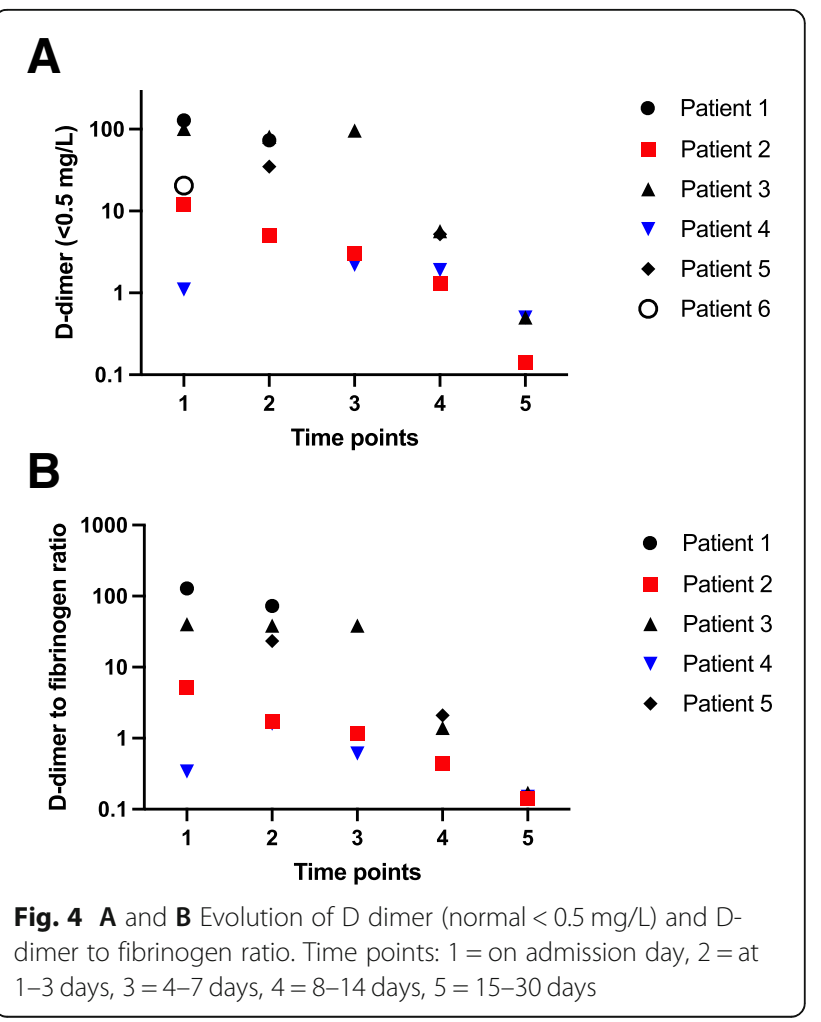


Table 3 Course and outcome of danaparoid treatment

\begin{tabular}{|c|c|c|c|c|c|c|}
\hline Patient & 1 & 2 & 3 & 4 & 5 & 6 \\
\hline Danaparoid initiation -Days after admission & 1 & 6 & 2 & 0 & 0 & 4 \\
\hline Route of administration & iv & SC & sc & sc & SC & SC \\
\hline Initial sc. daily dose $(U)$ & No & 2500 & 1500 & 3000 & N/A & N/A \\
\hline Anti-FXa (U/mL) Median & 0.23 & 0.31 & 0.33 & 0.23 & N/A & N/A \\
\hline D-Dimer after 4-7 days of danaparoid therapy & N/A & 1.7 & 11.8 & 1.9 & 5.2 & N/A \\
\hline Bleeding events & Yes* $^{*}$ & No & No & No & No & No \\
\hline Outcome & Fatal & Recovery & Recovery & Recovery & Recovery & Recovery \\
\hline
\end{tabular}

$*=\mathrm{ICH}, \mathrm{N} / \mathrm{A}=$ not available

activation (Table 2). Danaparoid therapy and its follow up showed a favorable course (Table 3). Subcutaneous danaparoid was generally initiated at the early phase of the hospital admission with an average treatment duration of 20 days (range 1-60 days) with twice daily dosing. Average initial daily dose was 2333 U (range 1500 $3000 \mathrm{U}$ ). Median anti-FXa activity levels remained at the lower range of recommended scale, $0.3 \mathrm{U} / \mathrm{mL}$ (Fig. 5). D-dimer levels after one week of danaparoid treatment significantly declined compared with the initial phase, and the one-week mean levels were $5.2 \mathrm{mg} / \mathrm{L}$ (range $1.7-11.8 \mathrm{mg} / \mathrm{L}$ ). One clinically significant bleeding episode was associated with VITT as the CVST of patient 1 was complicated with progressive secondary $\mathrm{ICH}$, already present before danaparoid initiation.

\section{Discussion}

Our Finnish VITT cohort seems to be aligned with the earlier reports with respect to: clinical presentation, coagulation biomarker status and clinical outcome. Our mortality rate is close to the rate recently reported for a large UK cohort [23] (17 vs $22 \%$ ), and the only fatal outcome was the very first VITT case of the nation. At that time, an optimal treatment protocol, including upfront IVIG as the key to pathogenesis control, was only

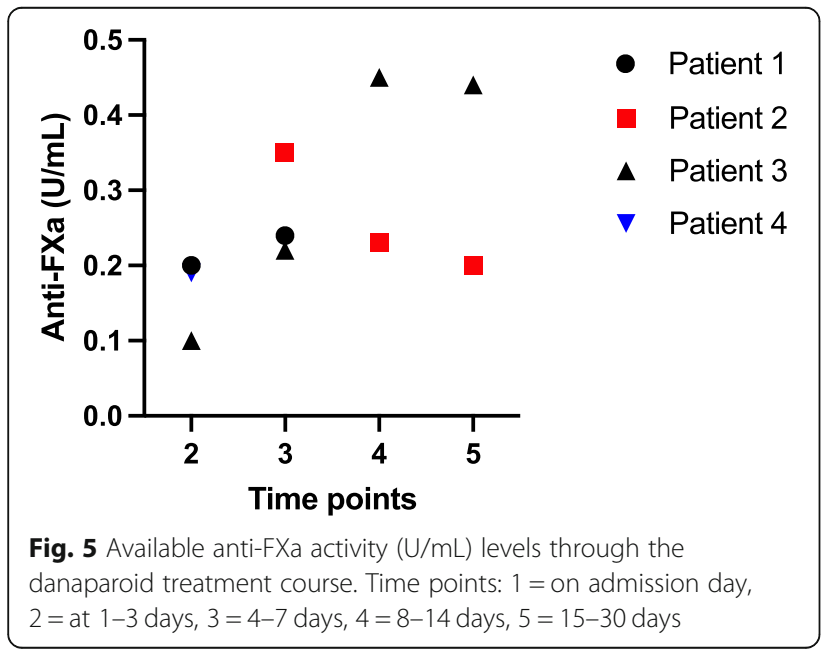

developing. In patients with CVST-VITT, higher mortality rates $(22-61 \%)$ are reported compared with VITT in general [23-26]. The potential of VITT for devastating outcomes calls for rapid recognition of cases. Since recognition of this new syndrome, several interim guidelines have been published to help frontline health workers and clinicians $[8,11,21,27]$. As a result improved identification of VITT and its management have led to a reduction in mortality [28].

Danaparoid, most frequently administered subcutaneously in our cohort, is a reasonable option for initial VITT anticoagulation supported by previously published guidance and experience from other anti-H/PF4 antibody - related disorders $[8,10-12]$. Due to its low overall negative charge density compared with heparin the ultra-large complexes with PF4 and the platelet activating antibodies will not form unlike in HIT. In addition, the absence of heparin-like domains explains its low propensity to cross-react with anti-PF4/heparin antibodies.

Our small study suggests that danaparoid administration and upfront IVIG were effective for VITT treatment since five of the six patients fully recovered without significant clinical sequelae. Subcutaneous administration is more practical to handle than continuous intravenous infusions, which direct thrombin inhibitor anticoagulants require. The effective subcutaneous treatment is easy to extend to the ambulatory mode, if needed. However, intravenous danaparoid, even at low infusion rates provides constant antithrombotic and anti-inflammatory activity levels compared with the peaks and troughs of intermittent subcutaneous injections and is the preferred option in severe cases. Our patients' danaparoid was monitored with anti-FXa activities, which were in the lower level of the target therapeutic range. The only bleeding complication was progression of an ICH which had occurred before danaparoid treatment initiation. This patient's high intravenous infusion rate coupled with a loading bolus of danaparoid was probably too intensive. Intracranial bleeding during CVST has previously proved to be a significant risk factor for detrimental outcome [29], also reported in the largest 
available VITT cohort [23]. Our results also compare favorably with previously reported use of danaparoid to treat VITT [17-20].

Our study has certain limitations. The sample size is only six patients and data are retrospective and observational with some missing data points (especially patients 5 and 6). Upon VITT diagnosis all patients received danaparoid so there is no comparison with other initial anticoagulant options. The availability of danaparoid is a national and tradition -based policy reserved for patients, who are intolerant or allergic to heparin.

We did not use direct oral anticoagulants (DOAC) early on, as multiple, and also arterial thrombi had to be managed. In addition, despite some favoring data [30,31], there is scanty evidence concerning the safety and efficacy of DOACs in the management of these forms of thrombosis (i.e, CVST). Dabigatran has proven at least as good option as warfarin [31], which is not recommended in acute HIT due to its impairment of protein C and S [10,32].

To establish the optimal first-line anticoagulation of VITT and other PF4 antibody -related disorders, more research is needed, including prospective comparative studies and pathophysiological research [33]. Even if the role of adenoviral vector nCOV19 vaccination has diminished in many countries, it is important to gain and publish knowledge of VITT for future occasions. Although we recognize the pathogenetic aspects of VITT, we do not understand who will get it, and the syndrome is not limited to adenovirus vector nCOV19 vaccine exposure only. Rare but potentially disastrous immune thrombotic anti-H/PF4 antibody related syndromes are also likely to occur in clinical scenarios that do not involve vaccination [6].

\section{Conclusions}

Our clinical case series suggests that danaparoid may be a rational option for initial anticoagulation of VITT together with upfront IVIG. Danaparoid has pharmacodynamic advantages and seemed to be well tolerated by our patients.

\section{Acknowledgements}

We appreciate the patients giving their permit to publish their data. The personnel of Coagulation Disorders Unit and HUSLAB at Helsinki University Hospital is thanked for their continuous commitment to manage coagulation abnormalities.

\section{Authors' contributions}

All authors contributed to the study design and writing process. Authors 1 and 2 collected data from health records and visualized the data. The authors read and approved the final manuscript.

\section{Funding}

Our study did not obtain any funding.

\section{Availability of data and materials}

We are open for data sharing, please contact the corresponding author (riitta.lassila@hus.fi) if needed.

\section{Declarations}

Ethics approval and consent to participate

Yes

\section{Consent for publication}

Yes

\section{Competing interests}

Harry Magnani was involved with the clinical development of danaparoid from 1980 to 2000 and in retirement has provided consultant services to various MAHs including the current license holder Aspen Pharma. All other authors declare no competing interests.

\section{Author details}

'Division of Internal Medicine and Rehabilitation, Department of Internal Medicine, Helsinki University Hospital, Helsinki, Finland. 'Helsinki University, Division of Anesthesiology, Department of Anesthesiology, Intensive Care and Pain Medicine, University of Helsinki and Helsinki University Hospital, Helsinki, Finland. ${ }^{3} \mathrm{Clinical}$ Research Institute HUCH, Helsinki, Finland.

${ }^{4}$ Independent Clinical Consultant, Schoutstraat, 54 Oss, The Netherlands.

${ }^{5}$ Unit of Coagulation Disorders, Department of Hematology, Comprehensive Cancer Center, Helsinki University Hospital, and Research Program Unit in Systems Oncology, University of Helsinki, Haartmaninkatu 8, 00290 Helsinki,

Finland. ${ }^{6}$ Finnish Institute of Health and Welfare, Helsinki, Finland.

Received: 28 October 2021 Accepted: 23 December 2021

Published online: 04 February 2022

\section{References}

1. Voysey M, Clemens SAC, Madhi SA, Weckx LY, Folegatti PM, Aley PK, et al. Oxford COVID Vaccine Trial Group. Safety and efficacy of the ChAdOx1 nCoV-19 vaccine (AZD1222) against SARS-CoV-2: an interim analysis of four randomised controlled trials in Brazil, South Africa, and the UK. Lancet. 2021; 397(10269):99-111. https://doi.org/10.1016/S0140-6736(20)32661-1 Epub 2020 Dec 8. Erratum in: Lancet. 2021 Jan 9;397(10269):98. PMID: 33306989; PMCID: PMC7723445.

2. Sadoff J, Gray G, Vandebosch A, Cárdenas V, Shukarev G, Grinsztejn B, et al. ENSEMBLE Study Group. Safety and Efficacy of Single-Dose Ad26.COV2.S Vaccine against Covid-19. N Engl J Med. 2021;384(23):2187-201. https://doi. org/10.1056/NEJMoa2101544 Epub 2021 Apr 21. PMID: 33882225; PMCID: PMC8220996.

3. Polack FP, Thomas SJ, Kitchin N, Absalon J, Gurtman A, Lockhart S, et al. C4591001 Clinical Trial Group. Safety and Efficacy of the BNT162b2 mRNA Covid-19 Vaccine. N Engl J Med. 2020;383(27):2603-15. https://doi.org/10.1 056/NEJMoa2034577 Epub 2020 Dec 10. PMID: 33301246; PMCID: PMC7745181.

4. Baden LR, El Sahly HM, Essink B, Kotloff K, Frey S, Novak R, et al. COVE Study Group. Efficacy and Safety of the mRNA-1273 SARS-CoV-2 Vaccine. N Engl J Med. 2021;384(5):403-16. https://doi.org/10.1056/NEJMoa2035389 Epub 2020 Dec 30. PMID: 33378609; PMCID: PMC7787219.

5. Schultz NH, Sørvoll IH, Michelsen AE, Munthe LA, Lund-Johansen F, Ahlen MT, et al. Thrombosis and Thrombocytopenia after ChAdOx1 nCoV-19 Vaccination. N Engl J Med. 2021;384(22):2124-30. https://doi. org/10.1056/NEJMoa2104882 Epub 2021 Apr 9. PMID: 33835768; PMCID: PMC8112568.

6. Greinacher A, Thiele T, Warkentin TE, Weisser K, Kyrle PA, Eichinger S. Thrombotic Thrombocytopenia after ChAdOx1 nCov-19 Vaccination. N Engl J Med. 2021;384(22):2092-101. https://doi.org/10.1056/NEJMoa2104840 Epub 2021 Apr 9. PMID: 33835769; PMCID: PMC8095372.

7. Scully M, Singh D, Lown R, Poles A, Solomon T, Levi M, et al. Pathologic Antibodies to Platelet Factor 4 after ChAdOx1 nCoV-19 Vaccination. N Engl J Med. 2021;384(23):2202-11. https://doi.org/10.1056/NEJMoa2105385.

8. Guidance from the Expert Haematology Panel (EHP) on Covid-19 Vaccineinduced Immune Thrombocytopenia and Thrombosis (VITT), https://b-s-h. org.uk/media/20075/guidance-version-22-20210903.pdf

9. Sánchez van Kammen M, Heldner MR, Brodard J, Scutelnic A, Silvis S, Schroeder V, et al. Frequency of Thrombocytopenia and Platelet Factor 4/ Heparin Antibodies in Patients With Cerebral Venous Sinus Thrombosis Prior to the COVID-19 Pandemic. JAMA. 2021:326(4):332-8. https://doi.org/10.1 001/jama.2021.9889 PMID: 34213527; PMCID: PMC8317004. 
10. Greinacher A, Selleng K, Warkentin TE. Autoimmune heparin-induced thrombocytopenia. J Thromb Haemost 2017 Nov;15(11):2099-2114. https:// doi.org/10.1111/jth.13813. Epub 2017 Sep 28. PMID: 28846826.

11. Guidance for clinical case management of thrombosis with thrombocytopenia syndrome (TTS) following vaccination to prevent coronavirus disease (COVID-19), Interim guidance 19 July 2021, World Health Organization.

12. Magnani HN, Gallus A. Heparin-induced thrombocytopenia (HIT). A report of 1,478 clinical outcomes of patients treated with danaparoid (Orgaran) from 1982 to mid-2004. Thromb Haemost 2006 Jun;95(6):967-981. https://doi. org/10.1160/TH05-07-0489. PMID: 16732376.

13. Magnani HN. Rationale for the role of heparin and related GAG antithrombotics in COVID-19 infection. Clin Appl Thromb Hemost. 2020;27: 1-26. https://doi.org/10.1177/1076029620977702.

14. HIT - Hepariinin indusoima trombosytopenia https://www.hematology.fi/ sites/default/files/uploads/hit_ohje_2021.pdf

15. Daviet F, Guervilly C, Baldesi O, Bernard-Guervilly F, Pilarczyk E, Genin A, et al. Heparin-Induced Thrombocytopenia in Severe COVID-19. Circulation. 2020;142(19):1875-7. https://doi.org/10.1161/CIRCULATIONAHA.120.049015 Epub 2020 Sep 29. PMID: 32990022; PMCID: PMC7643786.

16. Deruelle E, Ben Hadj Salem O, Sep Hieng S, Pichereau C, Outin H, Jamme M. Immune thrombocytopenia in a patient with COVID-19. Int J Hematol. 2020; 112(6):883-8. https://doi.org/10.1007/s12185-020-02943-5 Epub 2020 Jul 16. PMID: 32677007; PMCID: PMC7365304.

17. Thaler J, Ay C, Gleixner KV, Hauswirth AW, Cacioppo F, Grafeneder J, et al. Successful treatment of vaccine-induced prothrombotic immune thrombocytopenia (VIPIT). J Thromb Haemost. 2021;19(7):1819-22. https:// doi.org/10.1111/jth.15346 Epub 2021 Jun 11. PMID: 33877735; PMCID: PMC8362082.

18. Ramdeny S, Lang A, Al-Izzi S, Hung A, Anwar I, Kumar P. Management of a patient with a rare congenital limb malformation syndrome after SARS-CoV2 vaccine-induced thrombosis and thrombocytopenia (VITT). Br J Haematol. 2021;195(3):299. https://doi.org/10.1111/bjh.17619 Epub 2021 Jul 9. PMID: 34097311: PMCID: PMC8239676.

19. Walter U, Fuchs M, Grossmann A, Walter M, Thiele T, Storch A, et al. Adenovirus-Vectored COVID-19 Vaccine-Induced Immune Thrombosis of Carotid Artery: A Case Report. Neurology. 2021. https://doi.org/10.1212/WNL. 0000000000012576 Epub ahead of print. PMID: 34312301

20. Wolf ME, Luz B, Niehaus L, Bhogal P, Bäzner $H$, Henkes $H$. Thrombocytopenia and intracranial venous sinus thrombosis after "COVID19 vaccine AstraZeneca" exposure. J Clin Med. 2021;10(8):1599. https://doi. org/10.3390/jcm10081599 PMID: 33918932; PMCID: PMC8069989.

21. HUS - Astra Zenecan (AZ) rokotuksen jälkeiset tromboosit, diagnostiikka ja hoito. (Our hospital's guidance)

22. Safety of COVID-19 vaccines - Infectious diseases and vaccinations - THL. https://thl.fi/en/web/infectious-diseases-and-vaccinations/what-s-new/ coronavirus-covid-19-latest-updates/transmission-and-protection-corona virus/vaccines-and-coronavirus/safety-of-covid-19-vaccines (accessed May 5, 2021).

23. Pavord S, Scully M, Hunt BJ, Lester W, Bagot C, Craven B, et al. Clinical features of vaccine-induced immune thrombocytopenia and thrombosis. N Engl J Med. 2021;385(18):1680-9. https://doi.org/10.1056/NEJMoa2109908 Epub 2021 Aug 11. PMID: 34379914

24. Perry RJ, Tamborska A, Singh B, Craven B, Marigold R, Arthur-Farraj P, et al. CVT After Immunisation Against COVID-19 (CAIAC) collaborators. Cerebral venous thrombosis after vaccination against COVID-19 in the UK: a multicentre cohort study. Lancet. 2021;398(10306):1147-56. https://doi.org/1 0.1016/S0140-6736(21)01608-1 Epub 2021 Aug 6. PMID: 34370972; PMCID: PMC8346241.

25. Sánchez van Kammen M, Aguiar de Sousa D, Poli S, Cordonnier C, Heldne MR, van de Munckhof A, et al. Characteristics and Outcomes of Patients With Cerebral Venous Sinus Thrombosis in SARS-CoV-2 Vaccine-Induced Immune Thrombotic Thrombocytopenia. JAMA Neurol. 2021;78(11):1314-23. https://doi.org/10.1001/jamaneurol.2021.3619 PMID: 34581763; PMCID: PMC8479648.

26. Krzywicka K, Heldner MR, Sánchez van Kammen M, van Haaps T, Hiltunen S, Silvis SM, et al. Post-SARS-CoV-2-vaccination cerebral venous sinus thrombosis: an analysis of cases notified to the European Medicines Agency. Eur J Neurol. 2021;28(11):3656-62. https://doi.org/10.1111/ene.1502 9 Epub 2021 Aug 4. PMID: 34293217; PMCID: PMC8444640.
27. Ferro JM, de Sousa DA, Coutinho JM, Martinelli I. European stroke organization interim expert opinion on cerebral venous thrombosis occurring after SARS-CoV-2 vaccination. Eur Stroke J. 2021;6(3):CXVI-XI. https://doi.org/10.1177/23969873211030842 Epub 2021 Jul 20. PMID: 34746428; PMCID: PMC8564159.

28. van de Munckhof A, Krzywicka K, Aguiar de Sousa D, Sánchez van Kammen M, Heldner MR, Jood K, et al. Declining mortality of cerebral venous sinus thrombosis with thrombocytopenia after SARS-CoV-2 vaccination. Eur J Neurol. 2022;29(1):339-44. https://doi.org/10.1111/ene.15113 Epub 2021 Oct 1. PMID: 34536256; PMCID: PMC8652752.

29. Ferro JM, Canhão P, Stam J, Bousser MG, Barinagarrementeria F; ISCVT Investigators. Prognosis of cerebral vein and dural sinus thrombosis: results of the international study on cerebral vein and Dural sinus thrombosis (ISCV T). Stroke. 2004 Mar;35(3):664-670. https://doi.org/10.1161/01.STR.000011 7571.76197.26. Epub 2004 Feb 19. PMID: 14976332.

30. Ferro JM, Bousser MG, Canhão P, Coutinho JM, Crassard I, Dentali F et al. European stroke organization. European stroke organization guideline for the diagnosis and treatment of cerebral venous thrombosis - endorsed by the European academy of neurology. Eur J Neurol 2017 Oct;24(10):12031213. https://doi.org/10.1111/ene.13381. Epub 2017 Aug 20. PMID: 28833 980.

31. Ferro JM, Coutinho JM, Dentali F, Kobayashi A, Alasheev A, Canhão P, et al. RE-SPECT CVT Study Group. Safety and Efficacy of Dabigatran Etexilate vs Dose-Adjusted Warfarin in Patients With Cerebral Venous Thrombosis: A Randomized Clinical Trial. JAMA Neurol. 2019;76(12):1457-65. https://doi. org/10.1001/jamaneurol.2019.2764 PMID: 31479105; PMCID: PMC6724157.

32. Linkins LA, Dans AL, Moores LK, Bona R, Davidson BL, Schulman S, et al. Treatment and prevention of heparin-induced thrombocytopenia: antithrombotic therapy and prevention of thrombosis, 9th ed: American College of Chest Physicians Evidence-Based Clinical Practice Guidelines. Chest. 2012 Feb;141(2 Suppl):e495S-e530S. https://doi.org/10.1378/ chest.11-2303. Erratum in: Chest. 2015 Dec;148(6):1529. PMID: 22315270; PMCID: PMC3278058.

33. Pitkänen HH, Jouppila A, Helin T, Dulipati V, Kotimaa J, Meri S, et al. COVID19 adenovirus vaccine triggers antibodies against PF4 complexes to activate complement and platelets. Thromb Res. 2021;208:129-37. https://doi.org/1 0.1016/j.thromres.2021.10.027 Epub ahead of print. PMID: 34768097; PMCID: PMC8571998.

\section{Publisher's Note}

Springer Nature remains neutral with regard to jurisdictional claims in published maps and institutional affiliations.
Ready to submit your research? Choose BMC and benefit from:

- fast, convenient online submission

- thorough peer review by experienced researchers in your field

- rapid publication on acceptance

- support for research data, including large and complex data types

- gold Open Access which fosters wider collaboration and increased citations

- maximum visibility for your research: over $100 \mathrm{M}$ website views per year

At $\mathrm{BMC}$, research is always in progress.

Learn more biomedcentral.com/submission 